\title{
Analysis of moves and their lexical verbs of research article abstracts of Filipino and American writers
}

\author{
Abdul Wahid I. Tocalo \\ tocalo.ai@ndu.edu.ph \\ Notre Dame University, Philippines
}

\begin{abstract}
Rhetorical move analyses of research article (RA) abstracts have established variations across cultures and disciplines; however, other non-native users of English, such as Filipino writers, in other disciplines, such as applied linguistics, may still need a reference guide in abstract writing for they are underexplored in contrastive analysis to the best of the researcher's knowledge. Hence, this study compared the rhetorical moves in the RA abstracts of Filipino and American writers who are published in two research journals related to applied linguistics discipline. The study also explored the underlying lexical verbs in each move in all the abstracts. Findings revealed that the moves Situating the Research (STR), Presenting the Research (PTR), and Discussing the Research (DTR) were obligatorily used by both groups of writers. On the other note, the moves Describing the Methodology (DTM) and Summarizing the Findings (STF) were obligatory only among Filipinos, showing their tendency to deviate from the conventions in abstract writing of Americans who are considered native speakers and norm providers. Furthermore, this study details lists of lexical verbs that may be used to realize a rhetorical intent of a move. Hence, academic writing instructions may be informed by the rhetorical and linguistic realizations unveiled in this study.
\end{abstract}

Keywords: contrastive analysis, move analysis, research article abstract, lexical verb, Filipino writers, American writers 


\section{Introduction}

Composing clear and enlightening academic writing write-ups is an absolute necessity for survival and advancement in local and international discourse community. Specifically, writing research articles (RA), as one of the genres in academic writing that is viewed as a medium to trade and impart new information to academic community members (Flowerdew, 2005; Kanoksilapatham, 2013), calls for one's intricate writing skills to be internationally recognized through research publication. This is because composing publishable RAs requires language use awareness and features and organization of rhetorics (Amnuai \& Wannaruk, 2012). Zand-Vakili and Kashani (2012) supported the idea by claiming that research writers should be skilled with the text structure differences in order to advance their papers and achieve universal acknowledgment by publishing their papers in the international journals. Consequently, the need for the accessibility of one's RA through online scholastic web indexes has been given premium by scholars through writing a quintessential RA abstract. As Lores (2004) claimed, RA abstract serves as an entryway of readers to have a picture of an RA, of research journal's reviewers' determination for publication, and for research conferences to accept or reject an RA for presentation. Put differently, RA abstract is a medium through which an author's RA becomes accessible to and reach local or international academic discourse community.

Needless to say, writing an RA abstract becomes a pivotal skill among scholars. It is undeniable then that this section of an RA has remained in the limelight as far as research of language and linguistics scholars is concerned. In particular, it is a genre that has been analyzed using the moves it employs, as in the explication below.

As genres are purposed, staged activities, the move was chosen as the unit of analysis. A move is to be considered as a genre stage which has a particular, minor communicative purpose to fulfil, which in turn serves the major communicative purpose of the genre. (Santos, 1996, p. 485)

It is likewise noteworthy to bear in mind that a move may be smaller than an utterance (Richard \& Schmidt, 2002); hence, its realization in an RA abstract can be exemplified in one sentence, word, clause, or phrase, since an abstract is a condensed form of a whole RA. In fact, Santos (1996) also argued that a move can be identified depending on semantic and linguistic information given in a discourse. 
A myriad of move analysis studies of RA abstract have been carried out emphasizing the role of a particular discipline, such as Hartley (2003) in medicine, Huckin (2001) in biomedicine, Lon et al. (2012) in computer sciences, Samraj (2005) in biology, Martin-Martin (2005) in psychology, and Hyland (2000), Lores (2004), Pho (2008), and Santos (1996) in applied linguistics. Furthermore, the moves underlying an RA abstract were analyzed by comparing native and non-native speakers of English, such as Turkish and English-native speakers (e.g., Candarh, 2012), Persian and American writers (e.g., Ghasempour \& Farnia, 2017; Marefat \& Mohammadzadeh, 2013), and Iranian and American scholars (e.g., Abarghooeinezhad \& Simin, 2015; Chalak \& Norouzi, 2013; Nasseri \& Nematollahi, 2014). Finally, analyzing RA abstract rhetorical moves has also been zoomed in by including certain linguistic features under each move, such as the painstaking investigation on the preferences of verb tenses over distinctive moves (e.g., Chalak \& Norouzi, 2013; Ghasempour \& Farnia, 2017; Pezzini, 2003; Santos, 1996; Tseng, 2011), modality and verb tenses in each move (e.g., Salager-Meyer, 1991), and verb tense and voice (e.g., Abarghooeinezhad \& Simin, 2015). These earlier investigations are three-pronged, that is, disciplinary, contrastive, and linguistic dimensions of abstracts study, and the last two realms of analysis were the interest of the present study. As can be gleaned from the lines of inquiry, Nasseri and Nematollah (2014) specified that there is a requirement for more relative examinations that delve into RA abstracts in the field of applied linguistics by native and non-native users of English, such as between Filipinos and Americans. Based on the literature, a contrastive analysis concentrating on Filipinos and Americans in abstract writing has remained a neglect in research. Also, the fact there has been a heavy exploration of the verb tense operating in each move, other linguistic feature may then be an interesting focus to unearth, such as lexical verbs that may seem facilitative in the realization of a move. This category of English was already analyzed by Musa et al. (2015), but they focused on the methodology section of an RA. Therefore, the features of RA abstracts of Filipino and American writers can be more illustrated by its rhetorical moves with their certain linguistic realization.

The importance of juxtaposing the rhetorical moves of two groups of English speakers, such as native and non-native speakers, can be traced back with the idea of contrastive rhetoric as it explores cultural variations exemplified in discoursal structure. At an early period, such variations were even advanced as paramount in shaping programs of teaching English as a Second Language (ESL) (Taylor \& Tingguang, 1991). By advancing these rhetorical structures from 
different cultures in academic writing instructions, ESL learners may then be assisted in learning the expected writing conventions when attempting to forward their compositions in international platforms. As averred by Al-Khasawneh (2017), writers of RAs should keep themselves abreast of cultural differences of text structures to prevail in an international discourse community. AlKhasawneh added that if writers are not aware of these variations, they opt to use self-system of writing which could deny innovation and stress subjectivity in writing. He then emphasized that the idea of internationalization has been developing in the scholarly community, implying that the writing conventions of the Anglo-American academic community are needed to be acquired by other speakers of English in order to get worldwide acknowledgment. At the same time, Ventola (1994) espoused the idea that beginner writers need to know the customary linguistic realizations of those rhetorical moves or functions in a discourse. In the case of the current research, lexical verbs operating in each of the moves were analyzed. In other words, studies about RA abstracts are imperative to raise novice authors' mindfulness by furnishing them with more rhetorical and linguistic guidelines relevant to illuminating the teaching of ESL programs, such as English for Academic Purposes (EAP). The present inquiry then sought answers to the following questions:

1. How do Filipino and American writers structure their RA abstracts in applied linguistics discipline?

2. What lexical verbs operate in each of the rhetorical purposes of the moves in all the RA abstracts?

\section{Methodology}

\subsection{The Data}

A total of 40 RA abstracts which were all published in the field of applied linguistics were collected. The data comprised of 20 RA abstracts of Filipino writers and 20 RA abstracts of American writers. The abstracts of Filipinos were from the Philippine Journal of Linguistics (PJL), an international peer-reviewed journal and the official scholarly journal of Linguistics Society of the Philippines (LSP). Its editorial board members are coming from different highly acknowledged institutions in the Philippines and other countries. On the other hand, the source of the abstracts of Americans was The Annual Review of Linguistics (ANNU REV LINGUIST), a journal in the field of Applied Linguistics from the United States with $18 \mathrm{~h}$-index according to Scimago Journal Ranking. It has also maintained its quartile 1 status since its first year of publication until 2020. 
During the data collection, the researcher had a further online search of the profiles of the authors to guarantee their nationalities as Filipinos and Americans. The collection of the RA abstracts started from the most recent published articles in the two journals that have open access online. Such was done until reaching 20 abstracts in each group. While the selected number of RA abstracts appear limited, they are an acknowledged limitation of the study. Even so, a limited number of abstracts analyzed in the past have been made (e.g., Abarghooeinezhad \& Simin, 2015; Al-Kasawneh, 2017; Amnuai \& Wannaruk, 2012; Chalak \& Norouzi, 2013; Lores, 2004; Pho, 2008; Zand-Vakili \& Kashani, 2012).

\subsection{Analysis of Rhetorical Moves}

In analyzing the abstract moves, the current study used the abstract model of Santos (1996), a framework that was likewise utilized by a number of researchers (e.g., Abarghooeinezhad \& Simin, 2015; Doró, 2013; Lon et al., 2012; Pho, 2008; Tseng, 2011). The framework was selected in the present analysis because as Pho (2008) mentioned, it has been employed in abstract analysis in applied linguistics field and that it involves all the moves identified in a multitude of analyses on abstract moves. Doro (2013) also argued that the model is deemed a better parameter in analyzing RA abstracts because it includes richer information than other three- or four-move abstract models that were identified by other scholars in the past. Moreover, the present investigation adopted the idea of previous studies (e.g., Kanoksilapatham, 2013) in claiming that a move is obligatory if it occurs no less than $60 \%$ of the 20 abstracts of a group, and will be conceived as optional if its frequency is less than $60 \%$ of the 20 abstracts of a group. Thus, frequency count and percentage were used to obtain the number of occurrences of the rhetorical moves.

As can be observed in Table 1, the framework of Santos has five moves which are further explained by an indication of their functions in discourse. These functions are substantiated by guide questions that should be answered during the analysis of the moves. The abbreviations of each move were also used as the labels in the present analysis. 
Table 1: Five-Move Model for Abstract Analysis (Santos, 1996)

\begin{tabular}{|c|c|c|c|}
\hline Codes & Moves & Functions & Questions Asked \\
\hline STR & $\begin{array}{l}\text { Move 1: Situating the } \\
\text { Research }\end{array}$ & $\begin{array}{l}\text { Setting the scene for the current research } \\
\text { (topic generalization) }\end{array}$ & $\begin{array}{l}\text { What has been known } \\
\text { about the field/topic of } \\
\text { research? }\end{array}$ \\
\hline PTR & $\begin{array}{l}\text { Move 2: Presenting the } \\
\text { research }\end{array}$ & $\begin{array}{l}\text { Stating the purpose of the study, research } \\
\text { questions and/or hypotheses }\end{array}$ & What is the study about? \\
\hline DTM & $\begin{array}{l}\text { Move 3: Describing the } \\
\text { methodology }\end{array}$ & $\begin{array}{l}\text { Describing the materials, subjects, } \\
\text { variables, procedures }\end{array}$ & $\begin{array}{l}\text { How was the research } \\
\text { done? }\end{array}$ \\
\hline STF & $\begin{array}{l}\text { Move 4: Summarizing the } \\
\text { findings }\end{array}$ & Reporting the main findings of the study & $\begin{array}{l}\text { What did the researcher } \\
\text { find? }\end{array}$ \\
\hline DTR & $\begin{array}{l}\text { Move 5: Discussing the } \\
\text { research }\end{array}$ & $\begin{array}{l}\text { Interpreting the results/findings and/or } \\
\text { giving recommendations, } \\
\text { implications/applications of the study }\end{array}$ & $\begin{array}{l}\text { What do the results mean? } \\
\text { So what? }\end{array}$ \\
\hline
\end{tabular}

\subsection{Analysis of Lexical Verbs}

Noorli (2011, as cited in Musa et al., 2015) argued that lexis is the basis of a language. Lewis (1993, as cited in Musa et al., 2015) asserted that a construction of meaning is identified from fixed words than from fixed structures. Musa et al. then avouched that a grammatical expression and a rhetorical structure of a text are closely linked with each other. Supporting this is the idea of Bloch (2010, as cited in Musa et al., 2015), explicating that fixed grammatical expressions reflect the rhetorical purpose of a structure; hence, they assist one's understanding of the rhetorical intent of a structure. Musa et al. analyzed the lexical verbs that reflect the intent of the rhetorical moves in the methodology section of Engineering RAs. Examples are the lexical verbs obtain, purchase, and use which assist readers to realize the rhetorical purpose of the move describing the materials of the study in the methodology section. The same approach was carried out in the current inquiry to show a list of the lexical verbs in each of the abstract moves.

In the current analysis, the sentences below demonstrate the emphasized lexical verbs that help realize the rhetorical intent of STR move.

To date, few studies have explored the exact process of EFL students' response to assessment feedback on their speaking and writing performances. (Filipino Writer, Abstract 1) 
Much of the cross-cultural research into the speech act of apologizing has focused on the phenomenon of non-native communicative competence and less on cross-cultural data for their own sake. (American Writer, Abstract 2)

The lexical verbs explore and focus assist the readers that such sentences are under STR move and that they help generalize a research topic by showing what has been done by scholars in the past in the same line of inquiry, insinuating an idea that more explorations can be carried out.

It is likewise important to bear in mind that the lexical verbs taken under study were presented in their original forms, since the preference of tense of the verbs in abstract writing have been spelled out differently in previous studies. Hence, a writer may use the list of lexical verbs as a guide in structuring an abstract following their moves.

\subsection{Intercoder}

It is also important to note that two more coders in analyzing the moves and lexical verbs were taken in order to have reliable evaluations. The two coders have master's degree related to applied linguistics. In particular, all the coders discussed that they would have an agreement when they had similar classifications of the move and identification of the lexical verb realizing the intent of a rhetorical move. On the other hand, they would have disagreement when one of them had a different classification of the move and identification of the lexical verb. Consequently, the data would be reviewed based on the parameters and would be further discussed until reaching an agreement among them.

At the beginning, there was an orientation with the coders as to the discussion of the model used and lexical verb analysis to guarantee that they both have the same direction of analyses. During the orientation, a trial coding and/or analyses of $20 \%$ of the collected data were made by all the coders to ensure similar understanding. This was then followed by independently analyzing the moves and verbs. After studying the discussed parameters, all the coders achieved $100 \%$ agreement in their analyses of rhetorical moves and their underlying lexical verbs across all the collected data.

\section{Results and Discussion}

This section begins with the presentation and discussion of the frequencies of occurrences with the percentages of the moves in the RA abstracts of American and Filipino writers. It is followed by 
the presentation of the analysis of the lexical verbs used by both groups of writers in every move of the RA abstracts.

Table 2: The Frequency and Percentage of RA Abstract Moves of American and Filipino Writers

\begin{tabular}{|c|c|c|c|c|}
\hline \multirow[t]{2}{*}{$\begin{array}{l}\text { Santos' (1996) Five- } \\
\text { move Model }\end{array}$} & \multicolumn{2}{|c|}{$\begin{array}{l}\text { American Writers } \\
\mathrm{N}=10\end{array}$} & \multicolumn{2}{|c|}{$\begin{array}{l}\text { Filipino Writers } \\
\mathrm{N}=10\end{array}$} \\
\hline & Frequency & Percentage & Frequency & Percentage \\
\hline $\begin{array}{l}\text { Move 1: Situating the } \\
\text { research (STR) }\end{array}$ & 20 & $100 \%$ & 16 & $80 \%$ \\
\hline $\begin{array}{l}\text { Move 2: Presenting the } \\
\text { research (PTR) }\end{array}$ & 20 & $100 \%$ & 20 & $100 \%$ \\
\hline $\begin{array}{l}\text { Move 3: Describing the } \\
\text { methodology (DTM) }\end{array}$ & 10 & $50 \%$ & 20 & $100 \%$ \\
\hline $\begin{array}{l}\text { Move 4: Summarizing } \\
\text { the findings (STF) }\end{array}$ & 6 & $30 \%$ & 16 & $80 \%$ \\
\hline $\begin{array}{l}\text { Move 5: Discussing the } \\
\text { research (DTR) }\end{array}$ & 12 & $60 \%$ & 18 & $90 \%$ \\
\hline
\end{tabular}

Considering both groups of writers, Table 2 finally reveals that only move 1 (STR), move 2 (PTR), and move 5 (DTR) were considered obligatory, having move 5 (DTR) as the highly varied across the two groups based on their frequencies and percentages. On the other hand, the moves 3 (DTM) and 4 (STF) were reflected as optional. However, the two moves were obligatory only if Filipino writers are zoomed in. These findings merely illustrate the idea that even in abstract writing, cultural variations also occur among speakers of the English language. Eyeballing on the discussions of each of the rhetorical moves of the writers, the succeeding sections are presented.

\subsection{Move 1: Situating the Research (STR)}

This move serves as the onset of writing an RA abstract that sets a picture of a study by describing previous studies or a topic of an investigation in general. In the present research, there were 36 instances of the move 1 (STR) in all of the RA abstracts, accounting for 20 instances or 100\% among the American writers and 16 instances or $80 \%$ among the Filipino writers. Examples of this move in the RA abstracts are presented below: 
Research on creole tense-mood-aspect (TMA) systems began in earnest as a response to Bickerton's claim that there was a prototypical system shaped by a language bioprogram. (American Writer, Abstract 1)

In the past, the ESL/EFL field has intensively explored the effects of L1 to L2, yet overlooked the possible effects of L2 to L1. (Filipino Writer, Abstract 2)

The American and Filipino writers considered this first move as obligatory. This move contains a provision of a short background to contextualize their topics of investigations. This finding is surprising because it rejects numerous researchers who found that this move is the least frequently occurring move in the RA abstracts they analyzed; hence, an optional move (Abarghooeinezhad \& Simin, 2015; Al-Khasawneh, 2017; Chalak \& Norouzi, 2013; Ismail \& Shah, 2014; Pho, 2008; Tseng, 2011). Further, this finding neglects the analysis of Chalak and Norouzi (2013) who claimed that non-native speakers in their study tended to employ more the move 1 than native speakers did. Although Americans had 100\% while Filipinos had $80 \%$ use of the move in the present study, this observation still indicates a notion that giving a sort of previous knowledge about a research is an essential move by both groups of writers.

\subsection{Move 2: Presenting the Research (PTR)}

This move states the objective/s or purpose/s of a research by either describing research questions and/or research hypotheses. In the present investigation, all of the writers employed this move in all of their RA abstracts. The example extracts of this move from their RA abstracts are shown below:

In this review, I explore some of the advantages and disadvantages of using computational tools for historical linguistics. (American Writer, Abstract 2)

In order to add to the increasing number of studies on flash fiction, this paper examines along stylistic lines the flash fiction piece "Bettina" written by Gémino H. Abad, a renowned Filipino author. (Filipino Writer, Abstract 3)

Apparently, this move was reflected as obligatory in the abstracts of both writers. It is perhaps always given importance as this move presents what a study is all about. This result corroborates the findings of many studies that concluded move 2 as having the highest number of instances in RA abstracts, making the move compulsory or obligatory (Al-Khasawneh, 2017; 
Chalak \& Norouzi, 2013; Doro, 2013; Nasseri \& Nematollahi, 2014; Pho, 2008; Tseng, 2011). All of these results capitalise on the essence of showing the purpose of the study, since this move contains the very gist of an investigation in order to know the specific topic/s of the study.

\subsection{Move 3: Describing the Methodology (DTM)}

This move is when an author indicates how a study was done by describing its instruments, variables, subjects, and/or process. In the present study, this move is considered optional by American writers, having 10 occurrences (50\%) in their abstracts. However, this is obligatory among all Filipino writers with 20 instances in their abstracts (100\%). The examples below reveal this move from the abstracts of writers:

The primary objectives of this review are..., by means of a combination of holistic appraisals of fluency and techniques that target individual features of language. (American Writer, Abstract 5)

Anchored on Ben-Rafael et al.'s (2006) notion of top-down and bottom-up categorization of signs and Scollon and Scollon's (2003) concept of place semiotics, this paper examines how languages are represented in the LL of, the predominant language in, and the language ideologies in Binondo Chinatown. (Filipino Writer, Abstract 4)

The finding that shows this move as obligatory coheres with the findings of the previous studies (Al-Khasawneh, 2017; Chalak \& Norouzi, 2013; Doro, 2013; Nasseri \& Nematollahi, 2014; Pho, 2008; Tseng, 2011). On the other hand, the present study revealed that this move is optional by the American writers. This finding may be due to the fact that a majority of the analyzed abstracts are condensed forms of RAs in applied linguistics that are possibly theoretical studies; as a result, these abstracts do not feasibly give stress on the methodology of the study. Pho (2008) theorized in his study that this move largely occurred in his corpus because the abstracts reflect empirical studies that are primarily experimental in nature. As expected, writing such abstracts requires details of the methodology, since experimental research, which is more complex in approach, needs a clear explication as early as writing its abstract in order to avoid ambiguity among readers. Thus, it is safe to claim that the heavy reliance on using this move in abstract writing is also determined by the nature of research as to whether it is theoretical or highly empirical involving experimentations. 


\subsection{Move 4: Summarizing the Findings (STF)}

This move finally reports what a researcher mainly found after an investigation. In the present research, American writers utilized this move only 6 times (30\%), indicating its being an optional move. However, this move was employed 16 times (80\%) in the abstracts of Filipino writers,; hence, an obligatory move for them. Examples of this move from the RA abstracts are indicated below:

Creoles employ rich inventories of temporal and modal categories whose core meanings interact with the discourse context to produce different interpretations. The syntax of creole TMA also closely follows the universal hierarchy of functional heads proposed by Cinque. (American Writer, Abstract 1)

Paranan has two primary nominal markers: determiners and demonstratives. Pluralization in Paranan is marked by the use of the plural marker hidi, which may either be postnominal or prenominal. Besides gender, properties of common nouns, and borrowed nouns, Paranan has at least seven types of derived nouns. (Filipino Writer, Abstract 5)

Describing this move as obligatory supports the claims of the previous authors (AlKhasawneh, 2017; Candarh, 2012; Chalak \& Norouzi, 2013; Marefat \& Mohammadzadeh, 2013; Nasseri \& Nematollahi, 2014; Pho, 2008; Tseng, 2011). The finding that there is a difference of the occurrences of the move in the abstracts of the two Linguistics journals under study supports Doro (2013), who concluded that this move had also a considerable variation in the abstracts of the English studies journals he analyzed. The result that American writers were lesser in the utilization of this move could be attributed to a notion that they probably proceed to writing the last move, which contains interpretations or recommendations of a study. For this reason, they consider the last move as more important in writing an abstract, which is a section in RA that has a limited number of words required by a research journal when a researcher attempts to submit their study for publication.

\subsection{Move 5: Discussing the Research (DTR)}

This last move indicates a meaning/s of research findings by interpreting them. This may also constitute recommendations and/or implications of results of an investigation. In the current research, this move is considered obligatory by both groups of writers. There were 12 instances 
(60\%) of this move in the abstracts written by Americans and 18 instances (90\%) of this move in the abstracts of Filipinos. Examples of this move from both groups are revealed below:

This view has broad implications for the architecture of the human language system and provides a useful framework for integrating largely independent research programs on comprehension and production by both constraining the models and uncovering new questions that can drive further research. (American Writer, Abstract 9)

Further speech acts studies in the context of CMC should be innovated focusing on other aspects such as different genres or devising a speech acts model of virtual academic debating. (Filipino Writer, Abstract 8)

This result rejects the studies of Doro (2013) and Nasseri and Nematollahi (2014), who claimed this move as optional and the least used in abstract writing. The finding that $60 \%$ of the American writers used this move somehow supports the claim of Pho (2008), who considered this move as fairly common in the abstracts he investigated. Moreover, this finding disproves the investigations of Al-Khasawneh (2017) and Li (2011), who illustrated that native speaker of the English language more frequently used this move than non-native speakers of the language did. Therefore, the non-native speakers in the current study give more stress on providing implications of their research findings or inviting future scholars to conduct a similar study in the same field.

The fact that both the research journals as the sources of the analyzed abstracts in the present study require only 150 words in writing an abstract in its submission guidelines for publication, the findings above solidify then the idea that there is an existence of cultural variations exemplified in the discoursal structure of academic writing. In particular, these differences in abstract writing between American and Filipino writers are feasibly driven by cultural differences and expectations of the community the writers are engaged in (Candarh, 2012). The fact that the groups under study are from two different cultures, Candarh added that situatedness of writing could be a motivating factor even in abstract writing. This notion is more theoretically pronounced in the principle of contrastive rhetoric. Put differently, the first language background, cultural attributes, expectations of discourse community, influence of standard Englishes in a localized English, and/or even personal writing style can be the underlying factors. Moreover, it is interesting to point out that Filipino writers more frequently used the five moves in abstract writing than American writers did. This observation strengthens the idea that Filipinos as ESL speakers belong to the outer circle of English of (Kachru, 1992,1996) and is described as norm developing. 
Consequently, they develop their own norm by employing certain conventions in writing that are deviant of the norms established by the American writers, who are described as norm providing that belong to the inner circle of English of Kachru. In this regard, Kachru argued that language standards cannot be solely confined to one circle of English.

\subsection{Lexical Verbs Used in the Rhetorical Moves}

After manual analyses of the coders on the lexical verbs that were used to reflect the rhetorical purposes of each move based on the descriptions of the moves by Santos (1996), Table 3 details the lexical verbs used by all the writers in every move in their RA abstracts. The verbs in the lists are presented in alphabetical order from highest to lowest frequencies of use in the abstracts.

It should be noted that as described in the methodology section of this paper, the lexical verbs listed here are presented in their original forms, since preferences to verb tenses were varied in the findings of previous researches. Likewise, the verbs here are not associated solely to one rhetorical move, since a verb may also be used to realize rhetorical purposes of more than one move.

Table 3: Lexical Verbs in Each Rhetorical Moves

\begin{tabular}{|c|c|c|}
\hline $\begin{array}{l}\text { Santos' Five Moves of Abstract Writing } \\
\qquad(1996)\end{array}$ & Lexical Verb & Frequency \\
\hline \multirow[t]{15}{*}{ Move 1: Situating the research (STR) } & examine & 4 \\
\hline & explore & 4 \\
\hline & make & 4 \\
\hline & use & 4 \\
\hline & witness & 4 \\
\hline & arise & 2 \\
\hline & assemble & 2 \\
\hline & begin & 1 \\
\hline & belong & 1 \\
\hline & do & 1 \\
\hline & experience & 1 \\
\hline & formulate & 1 \\
\hline & overlook & 1 \\
\hline & progress & 1 \\
\hline & provide & 1 \\
\hline
\end{tabular}




\begin{tabular}{|c|c|c|}
\hline & reveal & 1 \\
\hline & suggest & 1 \\
\hline & turn & 1 \\
\hline \multirow[t]{20}{*}{ Move 2: Presenting the research $(P T R)$} & argue & 6 \\
\hline & examine & 6 \\
\hline & discuss & 4 \\
\hline & investigate & 4 \\
\hline & seek & 4 \\
\hline & show & 4 \\
\hline & address & 2 \\
\hline & advance & 2 \\
\hline & arise & 1 \\
\hline & describe & 1 \\
\hline & explore & 1 \\
\hline & highlight & 1 \\
\hline & illustrate & 1 \\
\hline & imply & 1 \\
\hline & intend & 1 \\
\hline & offer & 1 \\
\hline & outline & 1 \\
\hline & present & 1 \\
\hline & review & 1 \\
\hline & trace & 1 \\
\hline \multirow{14}{*}{$\begin{array}{l}\text { Move 3: Describing the methodology } \\
\qquad(D T M)\end{array}$} & employ & 6 \\
\hline & use & 6 \\
\hline & describe & 4 \\
\hline & aim & 2 \\
\hline & anchor & 1 \\
\hline & ask & 1 \\
\hline & attempt & 1 \\
\hline & depart & 1 \\
\hline & examine & 1 \\
\hline & focus & 1 \\
\hline & lead & 1 \\
\hline & participate & 1 \\
\hline & select & 1 \\
\hline & serve & 1 \\
\hline
\end{tabular}


Move 4:Summarizing the findings (STF)

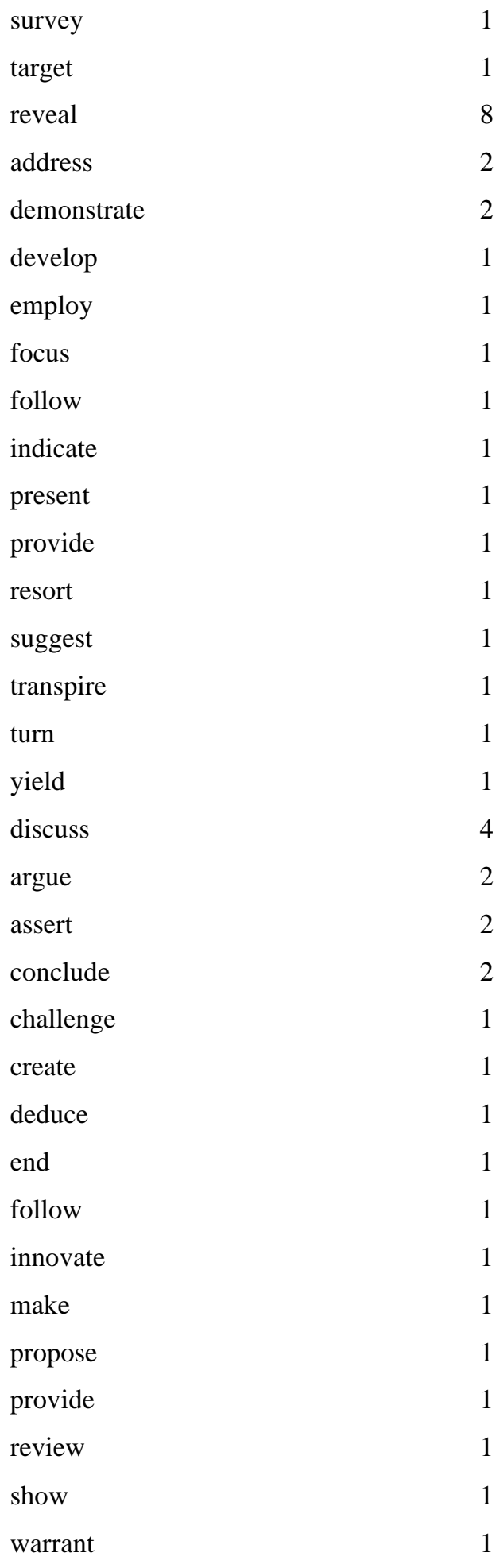

Furthermore, there were other sentences realized in a move that did not have a clear exemplification of a lexical verb which signals an intent of a rhetorical move because of the wordings of such sentences. An example of this case is presented below: 
The study of public signage referred to as linguistic landscape (LL) is an approach to understanding multilingualism. It has been used as an attempt to examine diversity and power relations in a multilingual environment such as the Philippines.

The extracts above are realized in the STR move. Such sentences do not contain a clear lexical verb that explicitly depicts the rhetorical purpose of the move. This is because the wordings of such sentences are written as a sort of background information or a piece of related literature that introduces the topic of the study. Unlike in the example sentence below that is represented in the STR move, the lexical verb explore in bold, with the meaning it carries, clearly depicts the rhetorical intent it serves. That is to say, the verb gives readers a straightforward idea that the sentence clearly provides a topic generalization by indicating what has been carried out in the past by researchers in similar line of inquiry, and that calls for a more exploration on the given topic.

To date, few studies have explored the exact process of EFL students' response to assessment feedback on their speaking and writing performances.

While acknowledging the idea that a realization of a rhetorical move is assisted by a lexical verb in discourse or sentence, the lists of lexical verbs presented in Table 3 are quintessential to be considered when writers, particularly novice researchers, structure their RA abstract following the five moves of Santos (1996). In academic writing instruction, RA abstract writing may then be shaped by coming up with more detailed lists of lexical verbs underlying each move. Specifically, the lexical verbs that have high occurrences in each of the moves may be prioritized in academic writing instruction in order for the ESL writers to be cognizant of the writing behavior of internationally recognized scholars when they compose their RA abstracts.

\section{Conclusion}

The present study aimed to juxtapose the rhetorical moves of American writers and Filipino writers in the RA abstracts in the field of applied linguistics. Using the five-move model of Santos (1996), the move 1 (STR), move 2 (PTR), and move 5 (DTR) were obligatory in the RA abstracts of both groups. The move 3 (DTM) and move 4 (STF) were optional among American writers, but obligatory among Filipino writers. This striking result reveals that Filipino writers follow all of the moves in their RA abstracts, while American writers neglect some of them. The high possible reason behind this epiphany is the nature of the RA whether it is theoretical or experimental. Being ESL speakers, Filipino writers may also attempt to develop their own writing conventions as 
belonging to the outer varieties of English, and veer away from what American writers establish as belonging to the inner varieties of English. Further, the findings amplify the idea that cultural differences occur even in abstract writing. Apart from the rhetorical moves, this investigation also indicated the lexical verbs that were apparent in realizing the rhetorical intent of every move observed in all the RA abstracts. In this way, beginning writers may have options available to their repertoire when attempting to use certain lexical verbs that help establish a function of a move. In other words, the writing conventions unveiled in the present study may illumine writers about the difference of two cultures as exemplified in the rhetorical moves and the use of lexical verbs in materializing such moves. This research helps contribute to many contrastive studies that serve as guide among novice scholars to get a high possibility of selling their RA abstracts in research journals and conferences for them to be internationally recognized.

This study acknowledges certain methodological limitations. First, it disregarded a robust control of the theoretical or experimental nature of the RAs represented by the abstracts. One can have a better distinction of the rhetorical moves if such a feature of RA abstracts is taken into account during data collection. Second, this research focused only on two journals related to applied linguistics field. Other fields and journals warrant further investigation to delineate more idiosyncrasies of certain moves in abstract writing. Third, this study only included a total of 40 RA abstracts, leading to the non-generalizability of the study. For this reason, a considerable number of abstracts as a corpus is more likely to be analyzed in the future to establish more the structural moves of writers and come up with more lists of lexical verbs operating in each move. Lastly, other linguistic features or categories of English evident in RA abstracts can be further explored to have more substantial linguistic realizations of the discourse.

\section{References}

Abarghooeinezhad, M., \& Simin, S. (2015). Analyses of verb tense and voice of research article abstracts in engineering journals. International Letters of Social and Humanistic Sciences, 47, 139-152. https://doi.org/10.18052/www.scipress.com/ilshs.47.139

Al-Khasawneh, F. M. (2017). A genre analysis of research article abstracts written by native and non-native speakers of English. Journal of Applied Linguistics and Language Research, 4(1), 1-13. 
Amnuai, W., \& Wannaruk, A. (2012). Investigating move structure of English applied linguistics research article discussions published in international and Thai journals. English Language Teaching, 6(2), 1-13. http://dx.doi.org/10.5539/elt.v6n2p1

Çandarl1, D. (2012). A cross-cultural investigation of English and Turkish research article abstracts in educational sciences. Studies about languages, 20, 12-17. https://doi.org/10.5755/j01.sal.0.20.1770

Chalak, A., \& Norouzi, Z. (2013). Rhetorical moves and verb tense in abstracts: A comparative analysis of American and Iranian academic writing. International Journal of Language Studies, 7(4), 101-110.

Doró, K. (2013). The rhetoric structure of research article abstracts in English studies journals. Prague Journal of English Studies, 2(1), 119-139. https://doi.org/10.2478/pjes2014-0013

Flowerdew, L. (2005). An integration of corpus-based and genre-based approaches to text analysis in EAP/ESP: countering criticisms against corpus-based methodologies. English for specific purposes, 24(3), 321-332. https://doi.org/10.1016/j.esp.2004.09.002

Ghasempour, B., \& Farnia, M. (2017). Contrastive move analysis: Persian and English research articles' abstracts in Law discipline. Journal of Teaching English for Specific and Academic Purposes, 5(4), 739-753.

Hartley, J. (2003). Improving the clarity of journal abstracts in psychology: the case for structure. Science Communication, 24(3), 366-379. https://doi.org/10.1177/1075547002250301

Huckin, T. (2001). Abstracting from Abstracts. In M. Hewings (Ed.), Academic Writing in Context: Implications and Applications (pp. 93-103). Birmingham: The University of Birmingham Press.

Hyland, K. (2000). Disciplinary discourses: Social interaction in academic genres. Longman.

Kachru, B. B. (1992). World Englishes: Approaches, issues and resources. Language Teaching, 25(1), 1-14. https://doi.org/10.1017/S0261444800006583

Kachru, B. B. (1996). World Englishes: Agony and ecstasy. The Journal of Aesthetic Education, 30(2), 135-155. https://doi.org/10.2307/3333196 
Kanoksilapatham, B. U. D. S. A. B. A. (2013). Generic characterisation of civil engineering research article abstracts. 3L: The Southeast Asian Journal of English Language Studies, 19(3), 1-10. http://ejournal.ukm.my/31/article/view/1653/2354

Li, Y. (2011). A genre analysis of English and Chinese research article abstracts in Linguistics and Chemistry. Published Master's thesis. San Diego University.

Lorés, R. (2004). On RA abstracts: from rhetorical structure to thematic organisation. English for specific purposes, 23(3), 280-302. https://doi.org/10.1016/j.esp.2003.06.001

Lon, C. E., Tan, H., \& Abdullah, A. N. (2012). Conveying communicative intent: Moves and metadiscourse in abstract writing. International Journal of Applied Linguistics and English Literature, 1(7), 56-65. http://doi.org/10.7575/ijalel.v.1n.7p.155

Marefat, H. \& Mohammadzadeh, S. (2013). Genre analysis of literature research article abstracts: A cross linguistic, cross-cultural study. Applied Research on English Language (Applied Research in English), 2(2), 37-50. https://doi.org/10.22108/ARE.2013.15469

Martín-Martín, P. (2005). The rhetoric of the abstract in English and Spanish scientific discourse: A cross-cultural genre-analytic approach (Vol. 21). Peter Lang.

Musa, N. F., Khamis, N., \& Zanariah, J. (2015). The structure of method section in Engineering $\begin{array}{lllll}\text { research } & \text { articles. }\end{array}$ http://dx.doi.org/10.5539/ass.v11n17p74

Nasseri, D., \& Nematollahi, B. (2014). A contrastive genre analysis of abstract of master of arts (ma) theses in applied linguistics written by native and non native speakers of English with respects to moves and move markers. Indian Journal of Scientific Research, 7(1), 1353-1366. http://www.ijsr.in/upload/312949916Microsoft\%20Word\%20\%20paper\%20537.pdf

Pezzini, O. I. (2003). Genre analysis and translation: An investigation of abstracts of research articles in two languages. Cadernos de Traduçao, 2(12), 75-108. https://dialnet.unirioja.es/descarga/articulo/4925541.pdf

Pho, P. D. (2008). Research article abstracts in applied linguistics and educational technology: A study of linguistic realizations of rhetorical structure and authorial stance. Discourse studies, 10(2), 231-250. https://doi.org/10.1177/1461445607087010

Richard, J. C., \& Schmidt, R. (2002). Dictionary of language teaching \& applied linguistics. Longman. 
Santos, M. B. D. (1996). The textual organization of research paper abstracts in applied linguistics. Text-Interdisciplinary Journal for the Study of Discourse, 16(4), 481-500. https://doi.org/10.1515/text.1.1996.16.4.481

Salager-Meyer, F. (1991). Reading expository prose at the post-secondary level: the influence of textual variables on L2 reading comprehension (a genre-based approach). Reading in a Foreign Language, 8(1), 645-645.

http://nflrc.hawaii.edu/rfl/PastIssues/rfl81salagermeyer.pdf

Samraj, B. (2005). An exploration of a genre set: Research article abstracts and introductions in two disciplines. English for specific purposes, 24(2), 141-156. https://doi.org/10.1016/j.esp.2002.10.001

Taylor, G., \& Tingguang, C. (1991). Linguistic, cultural, and subcultural issues in contrastive discourse analysis: Anglo-american and Chinese scientific texts. Applied Linguistics, 12(3), 319-336. https://doi.org/10.1093/applin/12.3.319

Tseng, F. P. (2011). Analyses of move structure and verb tense of research article abstracts in applied linguistics. International journal of English linguistics, 1(2), 27. http://dx.doi.org/10.5539/ijel.v1n2p27

Ventola, E. (1994). Abstracts as an object of linguistic study. In Writing vs. speaking: Language, text, discourse, communication, 333-352.

Zand-Vakili, E., \& Kashani, A. F. (2012). The contrastive move analysis: An investigation of Persian and English research articles' abstract and introduction parts. Mediterranean Journal of Social Sciences, 3(2), 129-137.

http://www.richtmann.org/journal/index.php/mjss/article/view/11008/10621 